\title{
Mapping the contours of humour: reflections on recent introductory studies ${ }^{1}$
}

\section{Conal Condren}

University of New South Wales, Australia

c.condren@unsw.edu.au

\begin{abstract}
Introductions to fields of study are almost a sub-genre in their own right, but are often resistant to direct comparison. The essay discusses four recent introductions to humour published by university presses, and what more broadly they may signify about disciplinary advertisement and consolidation. It emphasises a range of difficulties endemic to the study of humour arising from its interdisciplinarity, recent establishment, the variable range of humour and its putative universality; in which context it pays attention to Austinian performatives, puns and their translation, and to the shared propensity in these introductions to mythologise the history of humour theory. Most critical attention is paid to the studies that form almost polar opposites: Nilsen \& Nilsen, The Language of Humour and Attardo, The Linguistics of Humour.
\end{abstract}

Keywords: humour theory; myth; linguistics; translation; puns; academic communities

\section{Introduction}

This essay is a response to recent introductions to humour. Although they purport to provide maps we can all understand, introductions to fields of study can be difficult to compare. There is little in common between Kant's Prolegomena to Any Future Metaphysics (Kant [1783] 2004), and Peter Parley's Method of Telling about Geography to Children (Goodrich 1832). Written within fifty years of each other, they are otherwise poles apart. Kant's is a scoping study for his Critique of Pure Reason, a reintroduction to an abstruse and difficult work; Peter Parley's Geography and accompanying History are gentle, mildly propagandistic enticements designed to teach and amuse small children living in the United States, when the world was already nearly 6,000 years old (Goodrich 1832: 11, 141). There is no doubting the audiences targeted. Kant polemically shapes and answers his own questions; engagement is ideally an exercise in becoming a Kantian. Peter Parley's geographical queries follow his lessons for the children to show they have understood, or to encourage them to seek help if they have not. "What shape is the world or earth?, he initially asks the "little reader;" and later, which is the cruellest of European governments, and which the most polite nation (Goodrich 1832: 11, 65). Among the

\footnotetext{
${ }^{1}$ My thanks to Professor Christian Hempelmann and Dr. Jessica Milner Davis for astute criticism and encouragement.
} 
final tranche of questions on the world's diversity of religious belief is "What is the only true religion?" (Goodrich 1832: 119).

Introductions can thus run the gamut from being essential building blocks to readily dispensable scaffolding; they can also be catechisms to buttress orthodoxy. In academia, what is being introduced for whom, and to what end may not always be straightforward, but should show what is largely accepted in a given field, and reveal something of the dynamics of the publishing world and academic life. Indeed, irrespective of a target audience, a good introduction can effectively advertise an activity and aid its consolidation. There is, however, a price to be paid. As I shall illustrate, introductions are apt to trade in the simplistic, and perpetuate myths that are otherwise discounted, as Peter Parley teaches Archbishop Ussher's already discredited dating of the Creation (23 October, 4004 BCE).

Despite the lack of uniformly unmistakable marks, introductory works do at least have some common denominators: the requirement of accessibility, the assumption that the reader will have little knowledge, and the hope that the audience will be wide. On these bases, introductions should not be treated as failed or scaled-down monographs, whose common denominators are close to being the reverse - often at odds with orthodoxy, and inaccessible to any but the specialist. In practice, not all introductions conform to such a schematic dichotomy. In a number of respects, Salvatore Attardo's introduction, The Linguistics of Humour, edges closer to the monographic extreme (Attardo 2020); and my reactions to the Nilsens' Language of Humour indicate how difficult it can be to put monographic criteria of judgment entirely to one side (Nilsen \& Nilsen 2018). Although I cannot pretend to do justice to either, these two books will take up most direct attention as they indicate best the extremities of introductory surveys.

\section{General characteristics and the specific problems of humour}

The works that have stimulated these reflections (Carroll 2014; Nilsen \& Nilsen 2018; Eagleton 2019; Attardo 2020) are all by university presses whose reputations have depended upon monograph publication from which can flow precious little in the way of profit, but much in the currency of prestige. That, after all has been the point of such presses, whose taxable status is thus usually as charities. In contrast, the commercial press has almost invariably to consider profitability. That Cambridge, Oxford and Yale University presses have turned to the introduction may tell us a little about adjusting publishing priorities, or widening horizons. Nevertheless, the badge of a university press furnishes expectations of high quality; and certainly writing a good introduction is no easy matter.

Naturally, it must come from wide knowledge, but also requires a particular attention to what might be left out and ruthlessness in redaction. For these ends, the sense of audience is crucial. Writing a monograph or a journal article for an academic readership is in a way altogether easier; its character can be taken for granted, writing is for oneself and one's peers. Certainly, too rosy a picture can be painted of this. Vested intellectual interests can always be excited and toes easily trampled. Notwithstanding, the Introduction always involves some whistling in the dark.

Any established field of study will have specific problems for the introductory text. Those of humour studies are acute. Crucially, it is simply not a discipline but a broad subject matter, often of secondary interest in a number of more or less distinct modes of enquiry (Nilsen \& Nilsen 2018: 1-2). Humour is of sustained interest in sociology, politics, psychology, linguistics, and has been a more occasional focus in law, health studies, neuroscience, biochemistry and anthropology. The great totality of humour research, then, is not cohered by any single set of academic procedures, conventions, priorities and points of exclusion. It does not have a universally accepted and specialist conceptual vocabulary, though clearly Attardo would like to 
see one (Attardo 2020). As the Nilsens tellingly remark, posited universal theories of humour usually reflect the specific disciplines from which they have come (Nilsen \& Nilsen 2018: 1, 250-60). The unstated corollary is that those from other disciplines are likely to suspect an intellectual imperialism behind the desire for a common conceptual terminology. Thus, there is less that an introduction to the study of humour can take for granted than an introduction to accountancy or astrophysics; for these assume a certain kind of disciplinary literacy. In such cases, introductions can take a place in a more uniform and hierarchical pattern of education.

\subsection{Zones of exclusion}

That humour is so often an indication of what lies beyond it is bound to encourage a breadth of interest; yet only some areas of the study of humour are canvassed in these works. The Nilsens give attention to legal jokes and the oddities of legislation (Nilsen \& Nilsen 2018: 150-63); but in all these accounts, the lawyer's perspective in often different types of legal system, when confronting the criteria for licit expression, or concerning the allegedly humorous in the context of defamation, slander, censorship, tort and malicious intent, are matters hardly touched on. The neuroscientist, statistician, the biochemist, also wait in the wings; their presence would no doubt impossibly clutter the stage (though the Nilsens do pay some attention to medicine and therapeutic clowning).

Such absences are not unreasonable. There are lines of intellectual enquiry for which humour might be of only instrumental concern, and so attention to them in an introduction would sacrifice focus. If a neuroscientist uses cartoons to help stimulate chemical reactions in the brain, the humour may well be of subordinate interest to the electro-chemical responses vital to mapping neural pathways. Or a statistician might be attracted to humour principally to explore the methodological difficulties in providing sound evidence when relying on any porous or culturally complex classifier (Tavory 2014). In this way, statistical analyses of humour can be as treacherous as attempts to quantify party affiliations and voting patterns in early $18^{\text {th }}$ century England, when the party labels "Whig" and "Tory" meant different things to different people, and "party" itself was often a term of selective derogation. That is, what people are actually talking about when relying on a general term such as party or humour can be an arithmetical challenge in its own right.

This situation where understanding humour per se is a contingent means to a further end, is justifiably absent in an introduction; but awareness of the full range of research and scholarship potentially touching on humour may help explain why theory is apt to loom large in introductions to humour; for theory helps delineate and give coherence to enquiry. It can make the introduction more manageable, albeit at the risk of giving disproportionate attention to the abstract categories that those working on humour might use or take for granted. It can help mitigate or rationalise the distortions attendant upon the need to leave so much out of consideration. The Nilsen's are an exception here, for while being relentlessly inclusive, they give relatively little concentrated attention to theory, with, as I will suggest, deleterious consequences. More obviously, in introductions the tidiness of the joke is likely to assume centre stage, because of its typical self-contained brevity. It can thus easily stand in for humour per se: a convenient means of encapsulating a field becomes misleading.

\section{The variable scope and promotion of humour}

The putative common subject matter humour is not in this respect conspicuously helpful. Noël Carroll remarks that we see humour everywhere (Carroll 2014: 7). Indeed, but what are we actually seeing? Or, does some notion of humour provide the conceptual perspective that enables us to see everything in a certain way? The Nilsens briefly raise this possibility (Nilsen \& Nilsen 
2018: 1-3), only to convert an important epistemological issue into a mundane and approachable question of personal style. Yet whatever we see, as each of these authors is aware, we are not necessarily seeing jokes. As no one needs telling, humour is complex, contradictory, and difficult to determine. Robert Escarpit, in his still valuable introduction to humour (also a product of the university press), stressed the difficulties of providing an encompassing definition for anything as problematic, before giving more attention than most to the changing fortunes of the term and its cognates (Escarpit 1960: 5-32). This was appropriate as he was helping legitimate a difficult, even, he believed, indefinable loan word in French as a key to a neighbouring culture: in word and deed humour, as opposed to humeur was fundamentally an English language phenomenon. His problem, however, lay less in any formal process of definition as he supposed, than in determining how and when to apply the general term, and how far its usage corresponded to wit, for which in l'esprit the French do have a close equivalent.

The word humour, in keeping with the global reach of English, is now thoroughly internationalised, which only broadens its range, sustaining an illusion of universality. Attardo, rightly argues, and in line with Escarpit among others, that humour should best be regarded as an umbrella term, a general classifier imperfectly sheltering a range of specifically identified discursive phenomena such as irony, nonsense, wit, satire, hoax and jest. This I take to be entirely reasonable, although I think its implications are yet to be explored as fully as they might. The umbrella term is close to being a simulacrum of the parasolic nature of humour studies itself; and certainly the term's ecumenical standing can accommodate further changes and cultural differences. These can only make the terrain confronting introductions awkwardly uneven and shifting. Puns, for example, are largely treated as jesting forms of humour in English, an understanding carried without question into these works. In Japanese, however, puns are far less commonly associated with humour, so their status under the auspices of yummoa is more marginal (Nagashima 2006; Dybala et al. 2012:7-13). Ipso facto, the words for joke (kaikai, obsolete, jōdan or jōku) have a modified scope. In introducing the loanword humour (youmo) into Mandarin, Lin Yutang effectively excluded a whole class of jests (huaji) from its legitimate range; satire was also beyond the bounds of humour (Qian 2007: 283-4). Meanwhile back in English, satire has been largely narrowed to being just a type of humour, thus allowing Attardo to locate it unambiguously within humour's semantic field (Attardo 1994: 7). Only a hundred years ago this would have looked misleadingly eccentric.

\subsection{Uncertainties of focus}

Added to the problems of variable scope and application, is that of focus, whether the introduction is to humour, to its study, or even to its theory. These can be ambiguously linked and lead in different directions. An introduction to humour per se would have to be comprised principally of jokes, witty remarks, nonsensical propositions, ironic asides, silly images, the simply absurd and so forth; a joke book can, after all, put on display, if it cannot define, what a good deal of humour amounts to in a given culture. The Nilsens' work comes closest to this extreme. An introduction to the study of humour might do without many illustrative jokes. It might be an essay in institutional sociology, a study of how, when where, and under what administrative and financial constraints humour is recognised as a field of academic study. There might be few jests in a work devoted to refining theories of humour.

Underlying such niceties is the problem most likely to haunt any introduction, of whether humour is principally something to be celebrated or to be understood and explained. The presentation of a strong thesis can cut through a lot of these difficulties, but introductions are precisely the sorts of writing in which the cohering theme of argument needs to be muted in the interests of a reliable overview. Carroll is a touch apologetic about using incongruity theory as a way into humour as a whole. Giovanntonio Forabosco also chose to introduce humour by 
cautiously advancing incongruity theory as adequate for its understanding mainly in psychology (Forabosco 2014). A little like the ethics of book reviewing, the principal task is to give an outline of what the subject is about. Therein lies a problem, as I have indicated, outlines are apt to mislead by omission. Because of this, reviews of introductions are likely to be cursory. Much effort can garner little scholarly attention, or attention that is unduly critical because something has to be said about what should basically be known to specialists.

\section{The problem of recent origins}

As an academic enterprise, the formal study of humour is also relatively recent. Initially shaped by the preoccupations of psychology, it is now most notably an aspect of linguistics, sociology, politics and literary studies (Attardo 2014: xxxi). Consequently, introductions written before it was established, such as Leacock's (1935) and Escarpit's (1960) were little informed by the sort of theories setting out to define the nature and functions of humour that have since become meat and drink to those engaged in establishing and advancing an academic endeavour. Confrontation with the tensile claims of superiority, incongruity and release is now almost inescapable.

Because the area of study is relatively recent, introductions to it can also less confidently draw on traditions of introductory activity that have helped enhance established practices and presumptions found elsewhere in the academy. Anyone, for example, attempting to write a history of political thought can assume an orientating context of activity going back to the $19^{\text {th }}$ century; such histories amount to a sub-genre of political studies. Introductions to political science (and histories of political thought were invented to serve and promote the new discipline) are similarly long-standing. To be sure, this situation itself creates a problem of redundancy - why is a new introduction needed?

Answers, however, have hardly been beyond the resourcefulness of academics. In any case, for marketing reasons, publishers like to know that there is an existent area in which a proposed volume can be placed in order to gauge possible sales. Despite the promotional rhetoric we are all encouraged to employ, the bracingly original, or the rampantly interdisciplinary can be risky propositions to sell. For a highly mutable and cautious industry, it is better to deepen a wellploughed and trodden furrow than dig a hole somewhere else. Nowadays, with large student bodies there is the expectation, encouraged by the publishing industry, educational theory and the pressures of teaching practice that textbooks are indispensable. That is decidedly contrary to my experience. Nevertheless, humour studies are neither so assured, substantial, if one counts posteriors on seating, nor grounded in traditions of introductory iteration to make the new introduction such a relatively unproblematic project. The need to hunt that illusive Snark-like creature the general reader is still likely to be a complicating necessity - as the websites of university presses make clear.

\section{Significance and theory for the reader}

Taken together the introductions discussed here also provide a crude index for the changed status of studying humour in its own right and a broad interest in its results; they are signs of a furrow worth more working. Stephen Leacock hoped that humour might eventually be studied in universities (Leacock 1935: 5-7, 184). The necessity for any one of these books would have delighted him. Four within a few years of each other would have been an unlooked for cornucopia, strewn over a field of enquiry now needing to be tended, weeded, harvested, taken to market and sold; not only to students and general readers, but also, if only implicitly, to wellestablished neighbours in the academy. Potentially these are competitors or collaborators across the structures of the university. A good introduction can help solidify and enhance the 
independence of an institutional identity that still might be subject to absorption, or reabsorption into disciplines such as linguistics, psychology or sociology; by the same token, a bad one might arrest a noble cause.

Eagleton's study (Eagleton 2019) clearly has an eye principally on the general reader, the only audience Leacock could realistically have had in mind, although what counted as a general reader in 1935 might be unlike one of today. But in surveying conceptions of humour, Eagleton also draws particular attention to Francis Hutcheson (1694-1746), a philosopher who, he claims, deserves to be better known and elevated into a pantheon of humour theorists (Eagleton 2019: $111,115)$. Carroll's book is also focused on the attention of the otherwise educated, with an early nod towards those familiar with humour theory, and with which his work is then partially engaged (Carroll 2014); but the onus of extreme brevity, as part of a series of such works about significant areas of intellectual activity is indicative of how far the study of humour has become established. In contrast the Nilsens' volume, decidedly the most compendious in its range has the most specific focus on the American college student, for whom, it seems even their own theory, must take a back seat, (Nilsen \& Nilsen 2018: 1-2, 248-61). They refer to their theory as comprising features, functions and subjects of humour. As features and functions are aspects of any subject fit for study, it is difficult to see them as offering more than helpful captions for the student. They also occasionally allude to established theories, principally of release and incongruity, and underline the importance of ambiguity when they are discussing specifics. Attardo's emphasis is again different as it is on linguistic theory for the international community of humour scholars and advanced students engaged in humour research (Attardo 2020). It is a moot point how far this makes these studies complementary or incomparable.

\subsection{Accessibility and style}

Each passes any putative test of accessibility. Carroll's work is appropriately pithy and pellucid, although starting off by referring to a vast literature on humour as a "conversation" jarred (Carroll 2014: 4). Attardo's style is workmanlike and uncluttered. The Nilsens are clear and often engaging, although I also found their chatty anecdotalism self-indulgent. More importantly, however, periphrastic anecdote does serve valuably as a barrier against the reduction of humour to jokes. Nevertheless, the parochial focus on American popular culture was alienating, sometimes trivialising; but then, I am hardly a part of their intended audience and need to remind myself that their work is not a monograph. Put another way, the Nilsens make me feel ancient and curmudgeonly. Eagleton writes with flair and confidence, but the work is distractingly over-laden with jokes. Here, I think, we find someone falling foul of the ambiguous relationship between an introduction to humour (as jokes), so the more the merrier, and an account of the study of humour, for which any given joke is only evidence and elucidation of a certain sub-class of propositional structure (Hempelmann \& Attardo 2011; Ritchie 2014). To be sure, this is a matter of balance, but the contrast with Delia Chiaro's slim tome on the logic of joking is striking (Chiaro 1992). All her jokes are included to advance or qualify an argument, actually finding them funny is beside the point. If any of Eagleton's fall flat, they are wasted space. The general reader might, of course, find the jesting proclivity appealing, sales might tell. The work least reliant on being funny is Attardo's. This I did find congenial; but his is intended more to advance and refine the theoretical understanding of humour than to initiate an interest.

\section{Performatives and a general theory of humour}

As his is the most monographic of these introductions, its conceptual qualities and problems warrant further comment, not least as it is an extension of his earlier discussion of the same 
themes (Attardo 1994). In contrast to the Nilsens whose title displays a rather loose understanding of the word language, Attardo's is properly a linguistic investigation, extending some of his earlier work into adjacent communicative systems. Whether linguistic theories need be, or can be sufficiently accommodating to include, for example, music, dance and painting is clearly work in progress. Linguistic humour is largely propositional, playing with truth functions, contradictions and probabilities in language is predominant; and it is not clear to me that there can be such functions in dance or painting. To help deal with the issue, Attardo makes some superficial use of John Austin's philosophy of performative action; yet a more nuanced use of Austin would probably have proved distracting: the problem endemic to introductions in a nutshell. He treats the performative and the attendant Austinian notions of illocutionary and perlocutionary force broadly and as less troublesome than they have proved to be; but Attardo's discussion stands mainly as a prelude to a more detailed account of Semantic Script Theory that Attardo and Raskin have done so much to develop (Attardo 1994; Raskin 1985).

It is, however, some notion of the performative that holds at least some promise for the incorporation of non-linguistic sign-systems into the general theory that is yet to be established. At what cost to the discrimination of the class of performative verbs is another matter. To treat humour texts as performatives in any Austinian sense is questionable, for Austin's concerns were with analysing everyday statements in immediate contexts of discourse. This would naturally include much humour not least the script of a joke, but not extended humorous texts like Laurence Stern's Tristram Shandy (1759) or Lewis Carroll's nonsense poem Jabberwocky (1871). Using Austinian conceptions to make sense of them would be difficult without sacrificing philosophical interest and precision.

\section{The faith in universality}

Attardo, like the other authors here and many others is also committed to the view that humour is a universal, as Escarpit was not. Usually this is a rather unspecific expression of faith or enthusiasm. Hence Carroll's implicit imperative - we see humour everywhere, so we need to understand it. In contrast, Attardo does look at what he takes to be some of the entailments of universality, only to reveal the fragility or limited value of the belief, that sometimes sits uneasily with his insistence that humour should be regarded as an "umbrella term." Oddly, he regards humour as genetically encoded (Attardo 2020: 300); but it is hard to see what this might mean given the contingent range of discursive phenomena sheltered under the umbrella.

He also argues cautiously that all puns (taken as a sub-set of humour) must be translatable (Attardo 2020: 360-4). In the 18 ${ }^{\text {th }}$ century, Joseph Addison writing in the Spectator believed something similar, and concluded that those that are not translatable, are meaningless. I think, however, that the criterion of necessary translatability is too demanding. We might recognise that something was intended to be humorous, or would work as a pun in one language without finding it intelligible or identifiable as a pun in our own. Puns can arise only because of the specific phonetics and vocabulary of a given language and they are not necessarily humorous, or intentional. Some suitable features may be shared by groups of languages, so some puns might readily be translatable. Certainly an obscure pun in a source language might be explained to make it intelligible in its target tongue, but this would be to admit that the joke or pun itself is not being translated. There is a difference, in short, between translating a locution and conveying its status. The homophonic pun in utopia only works in spoken Greek, or perhaps in the way Greek was pronounced in the sixteenth century - the $u$ being a transliteration of the similarly sounded diphthongs prefixing topos, (place) indicating the non-existent (ou) or the best $(e u)$. Thomas More's Latin sub-title for Utopia is an oblique gloss on the pun, not a translation of it. European languages do not have the resources to translate logographic puns 
possible in Japanese kanji, but we might still reasonably understand enough of what is going on in a pictograph (Takanashi 2007) to place it under the aegis of humour. Attardo had no need to nail his colours to the mast of the universally accessible pun, but the problem of translatability runs deeper.

\subsection{Translating humour}

Translation is recognised to be a malleable notion, at its strongest amounting to pretty strict equivalence, at its weakest conveying only an analogous intelligibility. Much humour might be fairly easily translatable between reasonably similar languages; but universal translatability is a proposition that is most plausible as we approach the extreme of maximal equivalence. Leaving aside the difficulties raised by there being differing criteria for equivalence, the semantic substitution of terms for traffic directions, for example, would seem to be pretty straightforward, but this is hardly paradigmatic of translation across its full range. Thus, with translated poetry the process is creative. This is why poetic translation has traditionally been undertaken by poets, often for readers perfectly familiar with the original and its language. Translation, as Umberto Eco has persuasively argued, involves cultural as well as linguistic negotiation (Eco 2003). It is counterintuitive to think that translating humour or a humorously intended pun, is an exception, or needs to be if humour is a universal. Rather, it would appear to illustrate Quine's argument that synonymity of terms between and even within languages is never absolute (Quine 1960). It is a point reinforced by linguistic field theory on which Attardo draws. It is, certainly difficult to see how a joke about indefinite articles in English could be translated into a language that lacks that grammatical class altogether.

\section{Perpetuating the myths of humour theory}

Some version of a universality thesis is also accentuated by what seems remarkably commonplace in humour studies, the belief that theories of humour stem from antiquity: what is now taken to be universal has always been acknowledged. Here we have the clearest instance of the mythologising propensities of introductions. Attardo advances this notion of humour theory's antiquity (Attardo 2020: 19; also Attardo 1994: 19-25). Attaching an august lineage to the study of humour clearly has promotional appeal, and so can be expected in introductory works, but it does not bear much historical scrutiny. This is not least because it is heavily dependent on the effective equation of laughter with humour, or the assumption of a simple causative relation between the two: thus Attardo's assertion that laughter is the perlocutionary effect (the only one?) of humour (Attardo 1994: 13). Even if considered in isolation, laughter and humour are hardly co-extensive terms allowing us to see humour everywhere on the evidence of laughter (Attardo 2020: 300). Their becoming so closely associated is part of relatively recent linguistic and conceptual changes. As an occasional cognate term for jest, the word humour only begins to be used as a general classifier in England towards the end of the $17^{\text {th }}$ century, erratically becoming a porous one during the $18^{\text {th }}$, and modifying a predominantly negative attitude to laughter. Hitherto this physiological phenomenon had been understood in rather different terms. It seems also to have been only from the $19^{\text {th }}$ century that laughter became normally regarded as an expression of humour, and humour consolidated as praiseworthy by the invention of the negative antonym, humourless (c. 1850). As Daniel Wickberg has argued, we also have to wait until then for the notion of a sense of humour to be articulated (Wickberg 1993; 1998). Of the authors discussed, only Eagleton faces up squarely to the importance of a distinction between laughter and humour, albeit then forgetting all about it (Eagleton 2019: 16; cf. 37-40, 80, 90, 131). 
Certainly Attardo's work would have been better without the catechistic nostrums about Plato, Aristotle, Cicero, Quintilian, their definitions of humour, and without the "grandfather" of the superiority theory of humour, Thomas Hobbes (Attardo 2020: 20). Superiority is a theory of considerable power (Carroll 2014: 9-10) or so implausible it is almost funny (Eagleton 39). Either way, Hobbes is stuck with it. What we tell you four times must be true; but on the evidence provided, these authors show little acquaintance with what Hobbes actually wrote about laughter, not humour, nor sufficient familiarity with more than a paragraph from Leviathan (Condren 2020: 32-5). But to repeat, we are dealing here with introductions. Nevertheless, in effect, they help perpetuate communal myths, as Peter Parley helped keep alive an Ussher-like chronology of the world. Similarly, early encyclopaedias as synthesising cribs kept theories like humoral theory on life support when the word humour was beginning to have independent meaning and professional physicians were turning to other forms of explanation (for discussion, Yeo 2003; 2010). It remains, however, a tribute to Attardo's study in particular, that anyone seriously interested in exploring and explaining linguistic humour ought to engage with it; it is as close as we get to the introduction as a building block for advanced study.

\section{Democracy in America}

With a taste for imperious generalisation, Alexis de Tocqueville predicted that democracy in America would result in the triumph of the lowest common denominator. This may yet to be realised, nevertheless there is the starkest of contrasts between Attardo's focus on an educational minority and the Nilsen's single-minded attention to the American college student, leaving even the general reader hardly in sight. Easy accessibility is paramount and their text comes complete with power-point presentations (each concluding with images of gratuitous self-promotion) and questions to fix the attention of the instructor, points of departure. There are even introductory chapter outlines for those subject to distressed concentration (Nilsen \& Nilsen 2018: 3-12). Herein is clear recognition that humour must be traced well beyond the linguistic; but it may also indicate sensitivity to an increasing reliance on the visual among student bodies, as familiar with the intellectual minimalism of emoji as they are with extended prose. Irrespective, for the Nilsens the presence of purely visual humour is simply a manifestation of humour's variety; it is hardly treated as a problem standing in the way of a universal theory, of which I suspect they may be sceptical.

The strength of their work is to display a wide range of topics in which humour can always be found and enjoyed. Thus in encouraging students to look for humour themselves they do succeed in casting light principally on aspects of American popular culture. This achievement is not to be discounted, but the beam of attention shifts between heterogeneous topics so speedily that we are left with only a sketchy superficiality. Nothing, they insist, should be out of bounds given sufficient empathy with the subject; both censorship and the pressures of political correctness should be resisted (Nilsen \& Nilsen 2018: 3). Yet, as they discuss no criteria for the determination of sufficient empathy, they leave us with little more than a motherhood statement justifying eclectic enthusiasm. A short chapter on parody, satire and irony in art concludes with a list of famous artists who have incorporated humour in their work (Nilsen \& Nilsen 2018: 369); how, why, when and of what kinds we are not told. Cultural literacy is having heard of someone. It is time to move on.

The range of topics extends from humour in business, philosophy, sociology, to gerontology (jokes about the old), to journalism, the performing arts, naming, sporting mascots, rhetoric, religion, and late night television. This, apart from jokes about American politicians comes close to exhausting the topic of politics. The chapter on history is distracted by its attention to television sit-coms and the development of soap opera from American advertising. Much of 
what is discussed as humour in music, complete with the names of humorous composers (more cultural literacy), deals not with music but words, from hip-hop spelling to lyrics and libretti (Nilsen \& Nilsen 2018: 205-17, 234-7).

It is unclear whether humour is ontologically ubiquitous, is a function of epistemology, a way of seeing, or of ethics (requiring the imperative of empathy), or a variable mix of these possibilities depending on the topic already deemed humorous - a sort of umbrella term with holes in it. Consequently, I found no sustained discrimination between what we can see as funny and intentional humour, a problem with regard to making discriminate sense of irony. Irrespective of monographic expectations, there is something unsatisfactory here. Coherence is given principally by tone and the alphabetical order of chapter headings, one thing does indeed come after another. I'm left with the impression that we are not that far from the world of Peter Parley, especially given the authors' avuncular informality, except that Parley's little readers have grown into college students. This is why put less kindly, there is sometimes just an echo of Murphy A. Sweat giving the low-down on great lit. to the jocks before they go off to the game - he's from Yale (Crews [1964] 1972: 65-74). Frederick Crews brilliantly satirised the casebook attitude that enshrines the educationally unadventurous, and that may even have an origin in Peter Parley's Method of Telling About Geography. Indeed, the Nilsens' points of departure occasionally sound a trifle like Crews in full flight - write a 200 word essay "on a place - real or imagined - that has visual imagery." (Nilsen \& Nilsen 2018: 41). Perhaps an emoji for ironic amusement might suffice - but it seems that in emoji world there is no difference between satire, irony and sarcasm.

The questions raised by the formulaic and undemanding approach to teaching are disquieting ones of which the Nilsens must be well aware. They are experienced and knowledgeable teachers and every so often there is genuine insight in the flow of illustration: but is so little to be expected of levels of sustained student interest, capacity or, crucially, available time for study, that funny pictures and simple questions to stimulate opinions have to be provided? Are instructors assumed to be so lacking in expertise that such props are needed to guide them? These questions are neither rhetorical nor dismissive: the Nilsens may simply be biting bravely on the bullet points of educational reality in much of the United States. Above all, is celebration assumed to trump analysis; if so, what are the ramifications for taking the study of humour, or humour studies seriously? Given their own announced sense of humour, it is difficult to imagine that their introduction is excluded from its purview, and that they cannot see a certain irony in the final product having the imprimatur of a university press.

\section{Conclusion}

This work returns us to the beginning, accentuating the diversity of approach and purpose that the introductory survey can have. If humour might be considered an umbrella term, so might the introduction, leaving us with few clear and decisive criteria for comparison. Yet like humour the introduction also might be informative beyond its subject matter. Each of these volumes rehearses articles of faith that tell us more of the orthodoxies of humour studies than of humour's range or history. Moreover, it is interesting that in publishing the Nilsen's work Cambridge University Press is dipping its toe into shallow waters that are taken to be so extensive. How close we can come to a map of them without a vestige of land in sight is yet to be revealed.

\section{References}

Attardo, S. (2020). The Linguistics of Humour: An Introduction. Oxford: Oxford University Press. 
Attardo, S. (1994). Linguistic Theories of Humour. Berlin/New York: Mouton de Gruyter.

Attardo, S. (ed.). (2014). Encyclopedia of Humour Studies. California and London: Sage. 2 vols. Carroll, N. (2014). Humour: A Very Short Introduction. Oxford: Oxford University Press. Chiaro, D. (1992). The Language of Jokes: Analysing Verbal Play. London: Routledge.

Condren, C. (2020). 'The study of past humour: Historicity and the limits of method', in Derrin D. \& Burrows H. (eds.), The Palgrave Handbook of Humour, History, and Methodology, Cham Switzerland: Palgrave Macmillan: 19-41.

Crews, F. C. (1962, 1974). The Pooh Perplex: A Student Case Book. London: Barker.

Dybala, P., Rzepka, A., Araki, K., \& Sayama, K. (2012). 'Japanese puns are not necessarily jokes'. AAAI Technical Report FS- 12-02, 2012. Artificial Intelligence of Humour 7 (13). www.aaai.org

Eco, U. (2003). Mouse or Rat? Translation as Negotiation. London: Weidenfeld and Nicolson.

Eagleton, T. (2019). Humour. New Haven and London: Yale University Press.

Escarpit, R. (1960). L'Humour. Paris: Presses Universitaires De France.

Forabosco, G. (2014). Il settimo senso: Psicologia del senso dell'umorismo. con instruzione per l'uso. Mulazzo: Tarka.

Goodrich, S. G. (1830, 1832). Peter Parley's Method of Telling about Geography to Children. Peter Parley's Method of Telling about the History of the World to Children. Hartford, Conn: F. J. Huntington.

Hempelmann, C. \& Attardo, S. (2012). 'Resolutions and their incongruities: Further thoughts on Logical Mechanisms'. Humour: International Journal of Humour Research 24, 2 pp. 125-49.

Kant, I. (2004 [1783]). Prolegomena to Any Future Metaphysics (Prolegomena zu einer jaded Künfigen Metaphysic). Translated and edited by G. Hatfield. Cambridge: Cambridge University Press.

Leacock, S. (1935). Humour: Its Theory and Technique. London: John Lane, The Bodley Head. Nagashima, H. (2006). 'Sha-re: A widely accepted form of Japanese wordplay,' in Milner Davis, J. (ed.) Understanding Humour in Japan, Detroit: Wayne State University Press, pp. 75-83.

Nilsen, D. L. F. \& A. Pace. (2018). The Language of Humour: An Introduction. Cambridge: Cambridge University Press.

Qian, S. (2007). 'Translating "humour" into Chinese culture'. Humour International Journal of Humour Research 20 (3), pp. 277-95.

Quine, W. V. (1960). Word and Object. Cambridge, Mass.: MIT Press.

Raskin, V. (1985). Semantic Mechanism of Humour. Dordrecht, Reidel.

Ritchie, G. (2014). 'Logic and reasoning in jokes'. The European Journal of Humour Research 2 (1), pp. 50-60.

Takanashi, H. (2007). 'Orthographic puns: The case of Japanese kyoka'. Humour. International Journal of Humour Research 20 (3), pp. 239-59.

Tavory, I. (2014). 'The situations of culture: Humour and the limits of measurability'. Theory and Society 43, pp. 275-89.

Wickberg, D. (1998). The Senses of Humour: Self and Laughter in Modern America. Ithaca, N Y: Cornell University Press.

Wickberg, D. (1993). The Sense of Humour in American Culture, 1850-1960. Unpublished Ph. D. Thesis, Yale University.

Yeo, R. (2010). Encyclopaedic Vision: Scientific Dictionaries and Enlightenment Culture. Cambridge: Cambridge University Press.

Yeo, R. (2003). 'A solution to the multitude of books: Ephraim Chambers' Cyclopaedia (1728) as "The Best Book in the Universe"'. Journal of the History of Ideas 64 (1), pp. 61-72. 